\title{
Transient Investigation of Saltwater Upconing in Laboratory-Scale Coastal Aquifer
}

\author{
Antoifi Abdoulhalik ${ }^{1}$, and Ashraf A. Ahmed ${ }^{2, *}$ \\ ${ }^{1}$ School of Natural and Built Environment, Queen's University Belfast, David Keir Building, \\ Stranmillis Road, Belfast, BT95AG, UK \\ ${ }^{2}$ Department of Civil and Environmental Engineering, Brunel University London, Kingston Lane, \\ Uxbridge UB83PH, UK \\ *Corresponding author: Email: ashraf.ahmed@brunel.ac.uk Tel. 01895266971 Fax. 01895256392
}

\section{Abstract}

The objective of this research was to examine the response of seawater intrusion and retreat to freshwater abstraction from a well in laboratory-scale coastal aquifer under transient conditions. This has been done experimentally and numerically through qualitative and quantitative analysis. The laboratory experiments were completed in a two-dimensional laboratory tank for two beads sizes, namely $1090 \mu \mathrm{m}$ and $780 \mu \mathrm{m}$. The SEAWAT code was used for the numerical simulations. The experimental results showed that the vulnerability of the pumping well to salinization was higher for the low permeability aquifer, whereby the saltwater upconing process was observed at an abstraction rate $40 \%$ smaller in the lowerpermeability aquifer compared to the high permeability aquifer. In the lower permeability scenario, the inland penetration of the saline plume was up to $41 \%$ larger than in the higher permeability scenario, for an equivalent pumping rate increment. In addition, the process of decay (after the abstraction had ceased) of the wedge was slower in the lower permeability aquifer, which suggests a slower retreat of the wedge. The qualitative comparison of the shape of the saline plume and the quantitative comparison of the transient toe length data between experimental and numerical results showed excellent agreement. The flow velocity field analysis revealed that the local reduction of the magnitude of the flow velocity along the upper part of the interface was a major factor contributing to the saltwater upconing mechanism.

Keywords: Seawater intrusion; Saltwater upconing; Aquifer salinization; Laboratory experiments; Numerical modelling; SEAWAT 


\section{Introduction}

The over-abstraction of coastal groundwater leads to the landward incursion of oceanic saline water into fresh groundwater commonly known as seawater intrusion (SWI), which has already caused the contamination of many coastal aquifers around the globe (Ferguson and Gleeson, 2012). The main detrimental effects of SWI are the contamination of production wells and the loss of the available fresh groundwater sources (Werner et al., 2013). The horizontal extent of the saltwater plume along the aquifer bedrock, commonly known as the toe length, is often considered as the main metric quantifying SWI (Fig 1a). As the saline water intrudes deeper into the aquifer system and approaches the location of the pumping wells, large withdrawal of groundwater leads to the rise of the freshwater-saltwater interface below the vicinity of the well (Fig 1b), a process known as saltwater upconing mechanism (Reilly and Goodman, 1987). The salinization of pumping wells would occur following the mixing of only $250 \mathrm{mg} / \mathrm{l}$ of chloride after which freshwater is considered undrinkable as per WHO regulations (WHO, 2011), which is equivalent to less than $1 \%$ of seawater.
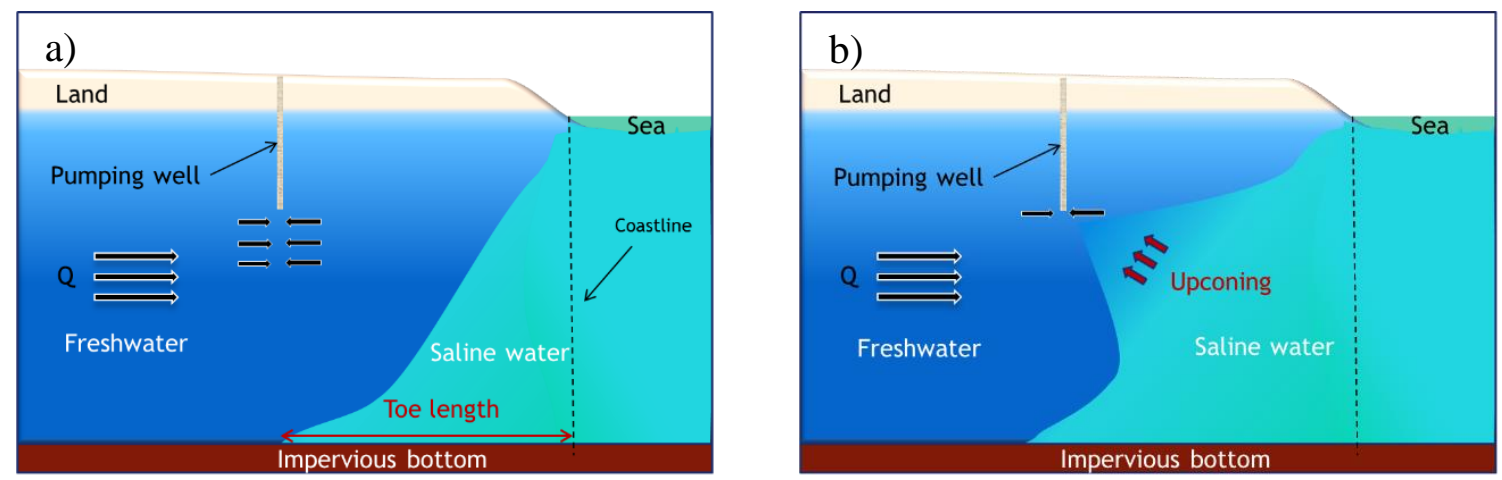

Figure 1 Simplified diagrams of a coastal unconfined aquifer showing a) the SWI mechanism and b) the saltwater upconing process. For the sake of simplicity, the transition-zone is shown as a sharp interface and the upconing is represented only below the well screen.

The issue of saltwater upconing was addressed by Dagan and Bear (1968) who developed mathematical equations and verified their results using series of sand box model experiments. Using the equations of Dagan and Bear (1968), Schmork and Mercado (1969) 
mathematically determined the critical pumping rate which was defined as the highest pumping rate at which the freshwater-saltwater interface can remain stable below the well without causing any salinization of the well discharge (Reilly and Goodman, 1987). Kashef and Smith (1975) simulated the extent of saltwater intrusion interface resulting from freshwater abstraction considering different well design parameters and various aquifer properties. Factors controlling the critical pumping rate and the extent of saltwater upconing were investigated either experimentally or numerically; however most of these investigations were based solely on qualitative analysis.

Several investigations have been conducted to simulate the upconing mechanism under transient conditions (Wirojanagud and Charbeneau, 1985; Johannsen et al., 2002; De Louw et al., 2013). Most of these numerical studies focused on 3D and/or axisymmetric models. Johannsen et al. (2002) performed a 3D saltpool as a benchmark problem of saltwater upconing in a porous media. Oswald and Kinzelbach (2004) compared their numerical results to the saltpool experimental data. They found that the upconing wedge was more pronounced in the numerical model and exhibited a significantly wider mixing zone. Shi et al. (2011) validated a steady-state 3D numerical model with a sandbox saltwater intrusion experiment under freshwater pumping condition. They conducted series of experiments which included scenarios of freshwater pumping and injection, and saltwater pumping. The freshwater-saltwater transition zone was considered sharp in their experiments.

The saltwater upconing mechanism in 2D laboratory-scale experiments has been investigated in few studies (Werner et al., 2009; Stoeckl and Houben, 2012; Mehdizadeh et al., 2015; Noorabadi et al., 2017). Werner et al. (2009) conducted saltwater upconing experiments in axisymmetric laboratory model and compared their experiments to the analytical solution of Dagan and Bear (1968). Their experiments were designed to evaluate the sensitivity of saltwater upconing behaviour to pumping rates and freshwater-saltwater density contrast. 
Their results showed that the influence of density was rather minor in comparison to the influence of pumping rate. Jakovovic et al. (2011) simulated the laboratory experiments of Werner et al. (2009) using fine discretization and small dispersion coefficients. The results showed in overall good agreement with those of the laboratory experiments, especially in the scenario of high pumping rate and low density contrast. Stoeckl and Houben (2012) completed physical experiments to compare the influence of pumping from horizontal and vertical well on the freshwater-saltwater interface. Their experiments showed that a horizontal well induced less upconing of the interface than a vertical well. Mehdizadeh et al. (2015) simulated the saltwater upconing in a sharp interface model and compared their results to laboratory tank experiments and dispersive model results, in terms of salt wedge shape and well salinity. Noorabadi et al. (2017) conducted 2D laboratory upconing experiments in steady state condition, varying the saltwater concentrations, the extraction rates and the depth of the well.

The impact of aquifer hydraulic conductivity on the saltwater upconing and decay (following pumping shut-off) mechanisms has so far never been explored. Although a lower hydraulic conductivity leads to greater drawdown in groundwater flow problems, for saltwater intrusion problems it cannot predict the rate at which the saline wedge moves towards a well, nor does it influence the rate at which the wedge retreats after pumping has ceased. It is thus worthwhile to investigate the impact of hydraulic conductivity on the saltwater upconing process.

The main purpose of this work was to explore the influence of aquifer hydraulic conductivity on the saltwater upconing and decay mechanisms using laboratory experiments and numerical simulation. While previous studies mainly focused on axisymmetric models (e.g. Jakovovic et al, 2011; Werner et al, 2009), which neglect the inland horizontal density-driven motion of the saltwater, this study presents an experimental investigation on the effect of pumping on seawater intrusion dynamics in an "inclined interface model", i.e. where the freshwater- 
saltwater interface is inclined such that a wedge-like shape of plume is formed, as commonly found in real world coastal aquifers (see Fig 1a). The study provides a quantitative analysis of saltwater upconing behaviour under transient conditions with high spatial and temporal resolution using automated image analysis technique (Robinson et al., 2015), while previous studies mostly used manual measurements. The distribution of the salt concentration within the freshwater-saltwater transition zone was herein analyzed for various pumping rates, which has never been done before considering that previous studies solely relied on visual observations. The study also presents for the first time maps of the flow velocity field in inclined freshwatersaltwater interface model, which provide a more realistic insight on the flow dynamics imposed by freshwater pumping during the upconing mechanism.

\section{Materials and methods}

\subsection{Experimental method}

The experiments were completed in laboratory flow tank which consisted of a central chamber joined by two side reservoirs, as shown in Fig 2. The dimensions of the central chamber were $0.38 \mathrm{~m} \times 0.15 \mathrm{~m} \times 0.01 \mathrm{~m}$. The chamber was filled with clear glass beads from Whitehouse Scientific ${ }^{\circledR}$ to simulate the porous media. The beads were carefully injected into the chamber under saturated conditions to minimize the entrapment of air into the system. The packing of the beads was completed in even-sized layers and each layer was carefully tamped to provide uniform compaction. The central chamber and the side reservoirs were separated by two fine mesh acrylic screens to ensure the confinement of the beads into the chamber. The aperture of the meshes were small enough $(0.5 \mathrm{~mm})$ to contain the glass beads and sufficiently large to allow circulation of the water from the side reservoirs.

The two reservoirs located at either side of the central chamber were used to impose the constant head boundary conditions. The left and right reservoirs were filled with fresh and saltwater respectively. A batch of saltwater solution was initially prepared before the 
experiments by mixing commercial salt to $200 \mathrm{~L}$ of freshwater at a concentration of $28.96 \mathrm{~g} / \mathrm{L}$, which yielded a density of $1020 \mathrm{~kg} / \mathrm{m}^{3}$. The density was carefully measured using a hydrometer (H-B Durac plain-form polycarbonate). Commercial red food colour was added to the saltwater solution to distinguish it from the freshwater.

Two LED lights (Camtree 600) were placed behind the experimental set-up to illuminate the porous media. A light diffuser was fixed to the back of the central chamber to ensure homogeneity of the light transmitted through the porous media. A high-speed camera IDT MotionPro X-Series with a resolution of 1280 x 1024 pixels and an 8-bit grayscale pixel depth was used to capture images of the experiments. The camera was set up such that it records 10 images each time it was triggered and the average of these images was used in the analysis. For the experiments, the camera was triggered every 30 second.

The pumping well was simulated using a Terumo Neolus hypodermic needle connected to a peristaltic pump Watson Marlow $101 \mathrm{U} / \mathrm{R}$ by a flexible hose (Maprene). The needle was $50 \mathrm{~mm}$ long with an inner and outer diameter of $0.7 \mathrm{~mm}$ and $1.1 \mathrm{~mm}$, respectively. The inner diameter of the hose was $4.8 \mathrm{~mm}$. The hose was maintained outside the porous media by a clamp stand placed behind the set up. The hose was carefully adjusted such that the tip of the needle was located $85 \mathrm{~mm}$ above the bottom of the tank, and $190 \mathrm{~mm}$ away from the sea side boundary. The needle was inserted vertically into the porous media and acted as a point sink whereby water was abstracted only from the tip of the needle. The position of the needle was the same in all the experiments.

The experiments were carried out for two bead sizes, namely $1090 \mu \mathrm{m}$ and $780 \mu \mathrm{m}$, to examine the effect of hydraulic conductivity changes on the saltwater upconing process. The hydraulic conductivity of the beads was estimated using in situ measurement within the experimental flow tank (Abdoulhalik et al. 2017). Various hydraulic gradients were 
successively imposed to the system, and the corresponding volumetric freshwater discharge was measured. The average hydraulic conductivity values were then subsequently derived using Darcy's law and were estimated at $85 \mathrm{~cm} / \mathrm{min}$ and $36 \mathrm{~cm} / \mathrm{min}$ for the beads of size 1090 $\mu \mathrm{m}$ and $780 \mu \mathrm{m}$, respectively.

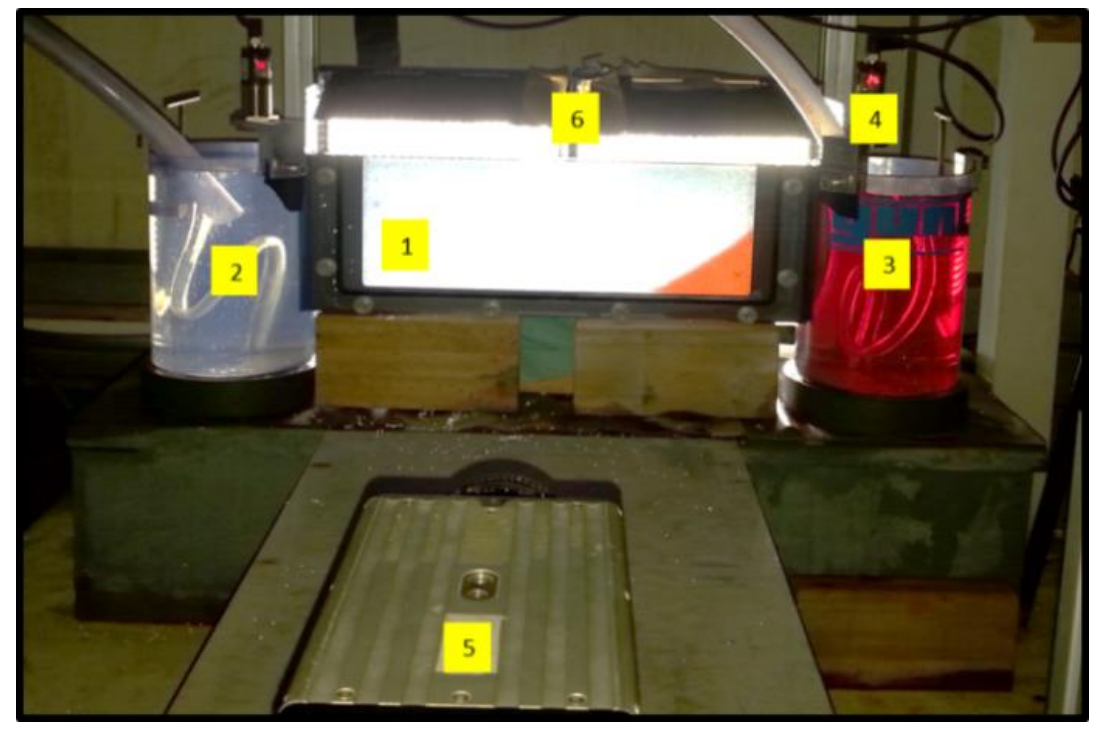

Figure 2 Photograph of the experimental set up; 1) porous media chamber; 2) freshwater reservoir; 3) saltwater reservoir; 4) ultrasonic sensors; 5) high speed camera; 6) LED lights.

\subsection{Experimental procedure}

To allow the determination the key SWI parameters using the automated image analysis technique (Abdoulhalik and Ahmed 2017a,b; Abdoulhalik and Ahmed, 2018), each experiment was preceded by a calibration procedure that enabled establishing a correlation between the light intensity transmitted through the porous media and the saltwater concentration. This light intensity-concentration conversion was done by flushing the aquifer with saltwater at different concentrations and record the light at each single pixel. A MATLAB code was then used to correlate the light intensity with the salt concentrations. More details of the automated image analysis technique are given in Robinson et al. (2015).

Prior to initiating the experiment, the left side reservoir was supplied with freshwater at constant rate (about $1.6 \mathrm{~mL} / \mathrm{s}$ ) from a large tank. The freshwater level in the left side reservoir 
was set high enough to allow the aquifer system to remain completely saturated. The overflow outlet in the saltwater reservoir was adjusted such that to maintain a constant head of 129.7 mm. Excess saltwater was continuously supplied into the right side reservoir to ensure the drainage of any possible floating freshwater to waste. The initial condition of the experiment was established by setting constant freshwater head of $135.7 \mathrm{~mm}$. This initial head boundary difference $(\mathrm{dh}=135.7-129.7=6 \mathrm{~mm})$ allowed the dense saline water to penetrate into the porous media until the system reached steady state condition. The pump was thereafter switched on with an initial pumping rate of $0.09 \mathrm{~mL} / \mathrm{s}$ and the system was allowed to reach a new steady condition. The pumping rate was then increased using a constant incremental step of $0.1 \mathrm{~mL} / \mathrm{s}$ and the system was allowed to reach equilibrium after each increment, and so until observation of the saltwater upconing process. The critical pumping rate (abstraction rate causing the upconing) was recorded and the pump was thereafter switched off to allow the saltwater to retreat towards the seaside boundary.

\subsection{Numerical model and procedure}

The purpose of performing numerical simulations was primarily to assess the consistency of the experimental data with the numerical predictions and thereafter used the developed models to better explain underlying phenomena by exploring the flow velocity field throughout the aquifer during pumping.

The MODFLOW family variable density flow code SEAWAT (Guo and Langevin, 2002) was used to perform the numerical modelling experiments. SEAWAT uses the output from MODFLOW (Harbaugh, et al., 2000) and MT3DMS (Zheng and Wang, 1999) to solve for the variable density fluid flow problem. It has been widely used to solve various variabledensity groundwater flow, such as the Henry problem, the Elder problem, and the HYDROCOIN problem (Guo and Langevin, 2002; Langevin et al., 2003). SEAWAT has also been successfully used in modelling SWI experiments involving freshwater head boundary 
variations (Abdoulhalik and Ahmed 2017a,b; Abdoulhalik et al. 2017; Abdelgawad et al. 2018; Abdoulhalik and Ahmed 2018).

The numerical model consisted of a rectangular domain of dimensions $38 \times 13 \mathrm{~cm}$ with uniform size mesh of $0.2 \mathrm{~cm}$ representing the porous media chamber. The longitudinal dispersivity was set at $0.1 \mathrm{~cm}$ and the transverse dispersivity was set at $1 / 10$ of the longitudinal dispersivity. The dispersivity values and the element dimensions provided numerical stability by satisfying the Peclet number criterion (Voss and Souza, 1987). A freshwater (C=0 g/L) hydrostatic boundary condition was applied on the left side boundary and a hydrostatic saltwater $(\mathrm{C}=28.96 \mathrm{~g} / \mathrm{L})$ boundary condition was applied on the right-side boundary. The time step of the simulations was set to $0.5 \mathrm{~min}$. The Pre-conditioned Conjugate-Gradient (PCG) package (Harbaugh et al., 2000) was employed to solve the flow equation and the third order total variation diminishing (TVD) scheme (Zheng and Wang, 1999) was used to solve the advection term.

The case for the $1090 \mu \mathrm{m}$ beads (hereafter 'case 1090') was adopted for the numerical validation. At the initial condition, the model domain corresponded to an entirely fresh aquifer. The first stress period was used to set the first steady state condition, whereby the freshwater and saltwater boundary were set at $13.57 \mathrm{~cm}$ and $12.97 \mathrm{~cm}$, respectively. This allowed the penetration of the saline water into the system. Once the first steady state was reached, the abstraction was initiated by simulating a well at the specified location with an initial discharge rate of $5.4 \mathrm{~cm}^{3} / \mathrm{min}(0.09 \mathrm{~mL} / \mathrm{s})$ for $50 \mathrm{~min}$ to allow the system to reach steady state. The discharge rate was then gradually increased using an increment of $6 \mathrm{~cm}^{3} / \mathrm{min}(0.1 \mathrm{~mL} / \mathrm{s})$. Each pumping rate increment was applied for a simulation time of $50 \mathrm{~min}$ similar to the experiment. Once the upconing process was observed, the pumping ceased, which allowed the retreat of the saltwater towards the coastline boundary. A summary of the parameters used in the numerical simulations is shown in table 1. 
Table 1 Summary of the numerical parameters.

\begin{tabular}{l|cc} 
INPUT PARAMETERS & VALUE & UNIT \\
\hline Domain length & 38 & $\mathrm{~cm}$ \\
Domain height & 13 & $\mathrm{~cm}$ \\
Element size & 0.2 & $\mathrm{~cm}$ \\
Hydraulic conductivity: & 85 & $\mathrm{~cm} / \mathrm{min}$ \\
Longitudinal dispersivity & 0.1 & $\mathrm{~cm}$ \\
Transversal dispersivity & 0.01 & $\mathrm{~cm}$ \\
Freshwater density & 1000 & $\mathrm{~kg} / \mathrm{m}^{3}$ \\
Saltwater density & 1020 & $\mathrm{~kg} / \mathrm{m}^{3}$ \\
Freshwater head & 13.57 & $\mathrm{~cm}$ \\
Saltwater head & 12.97 & $\mathrm{~cm}$ \\
Stress period & 50 & $\mathrm{~min}$
\end{tabular}

\section{Results and discussion}

\subsection{Saltwater upconing experiment}
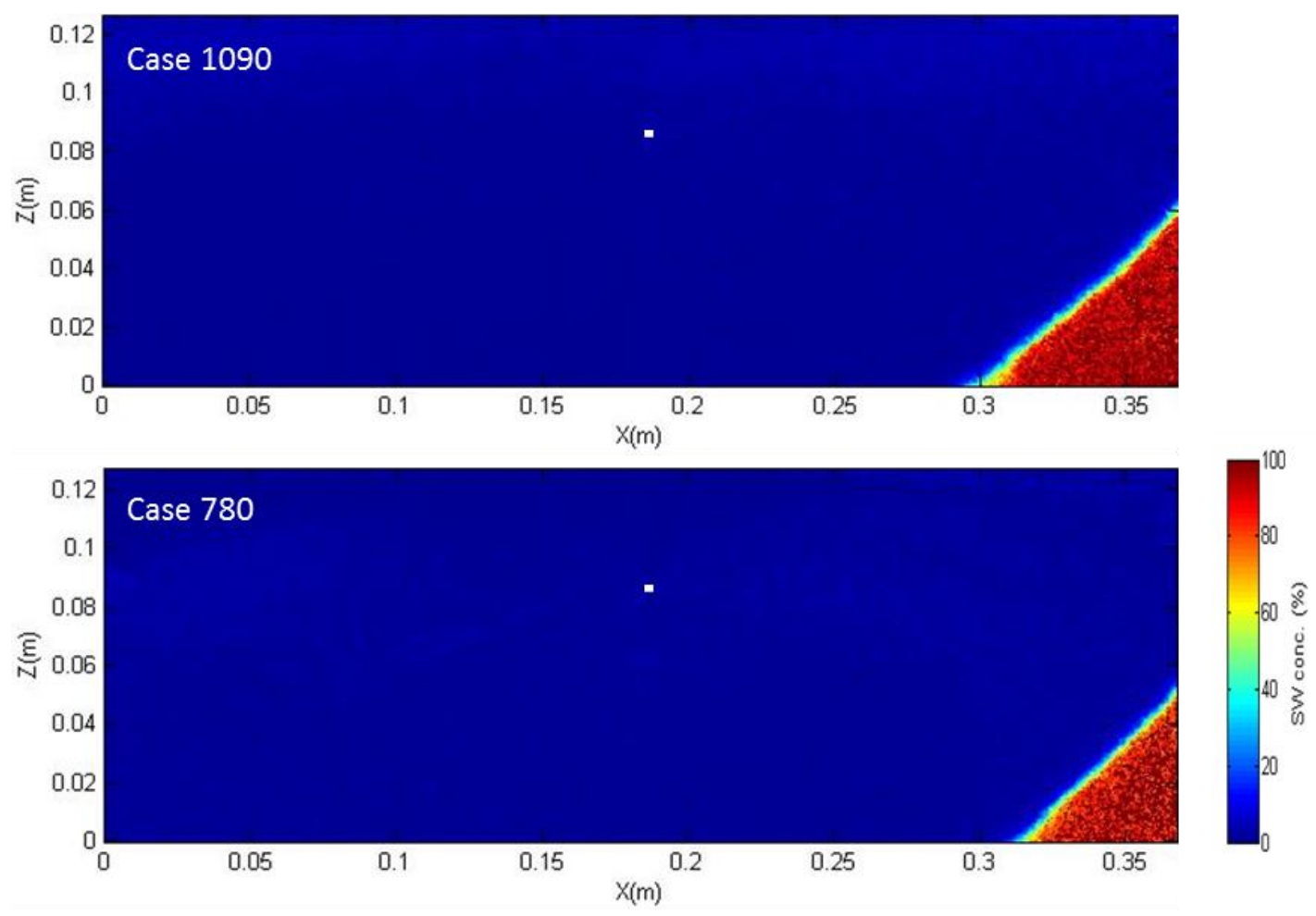

Figure 3 Initial steady state saltwater wedge after application of $\mathrm{dh}=6 \mathrm{~mm}$. A $100 \%$ salt concentration is equivalent to $28.96 \mathrm{~g} / \mathrm{L}$. 

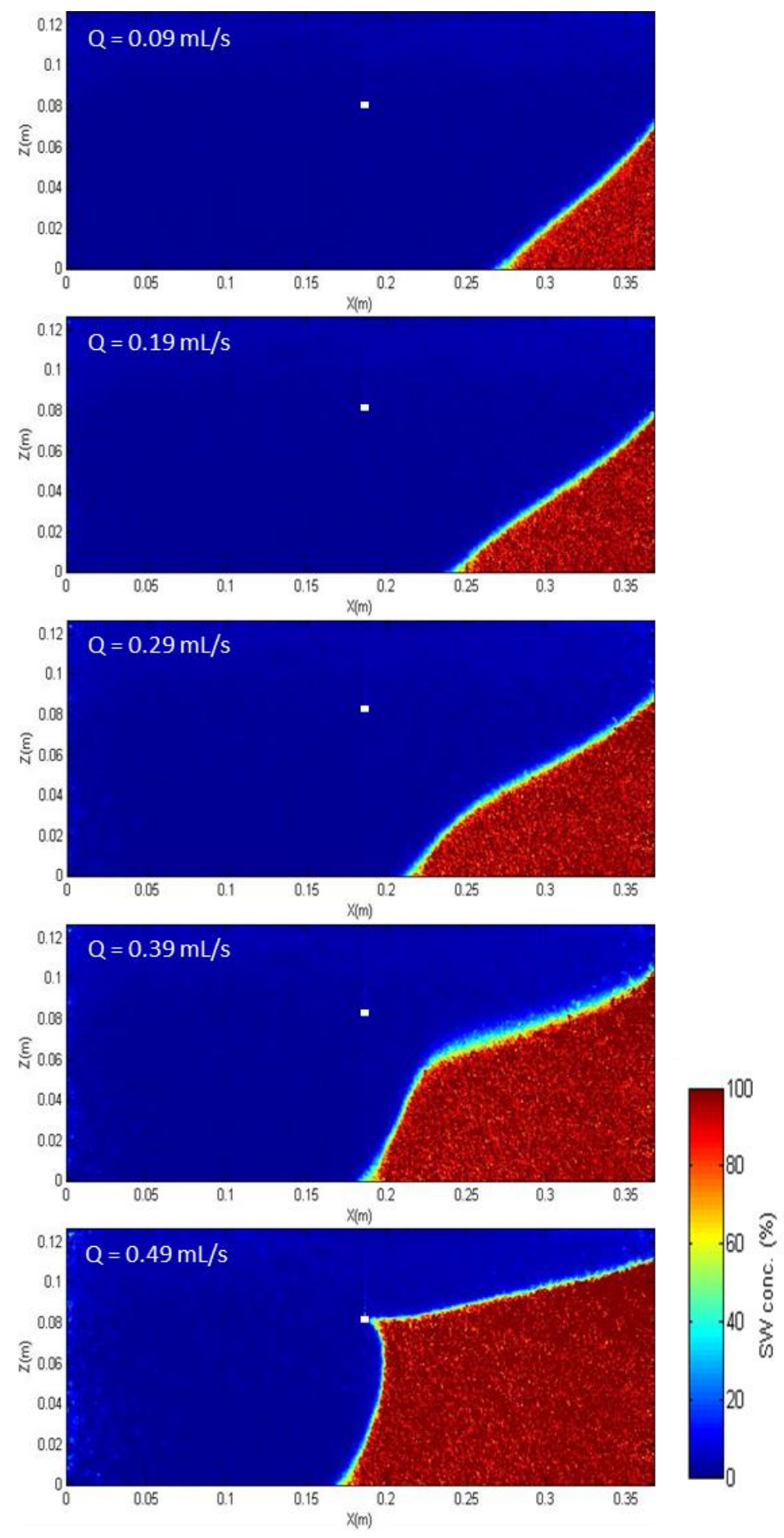

Figure 4 Experimental concentration colour maps showing the saltwater upconing process at different pumping rates in case 1090 .

Following the drop of the freshwater level down to $135.7 \mathrm{~mm}$ which decreased the head difference to $\mathrm{dh}=6 \mathrm{~mm}$, the saline water entered the aquifer system and intruded inland until it reached steady state condition. Fig 3 shows the concentration colour maps of the saltwater 
wedges at the initial steady state condition. In this figure and all the other figures showing contour maps, the salt concentration is shown as a percentage in which $100 \%$ salt concentration equals $28.96 \mathrm{~g} / \mathrm{L}$, which yields a density of $1020 \mathrm{~kg} / \mathrm{m}^{3}$. Experimental observations showed that it took relatively less time for the system to reach steady state in case 1090, where it occurred only after $23 \mathrm{~min}$ following the head change, while it took about $45 \mathrm{~min}$ in case 780 . As expected, the lower permeability media induced relatively slower migration of the denser fluid through the system, which agrees with Robinson et al. (2016).
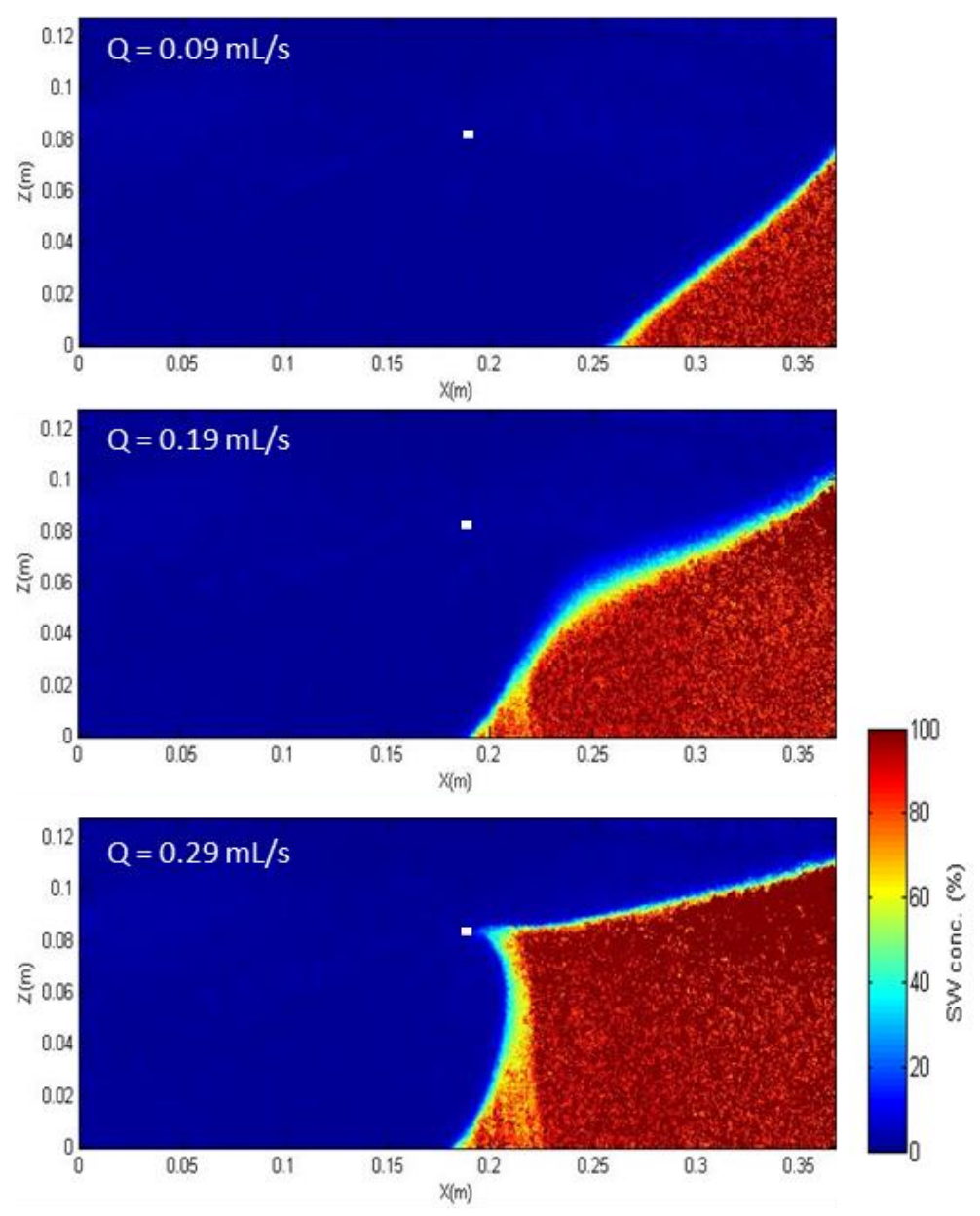

Figure 5 Experimental concentration colour maps showing the saltwater upconing process at different pumping rates in case $\mathbf{7 8 0}$.

The pump was thereafter switched on with a pumping rate of $0.09 \mathrm{~mL} / \mathrm{s}$ until the system reached a new steady condition. The pumping rate was then increased at a constant incremental 
step of $0.1 \mathrm{~mL} / \mathrm{s}$ until the observation of the saltwater upconing. The concentration colour maps of the saltwater wedge at steady state condition for each pumping rate are shown in Fig 4 for case 1090 and in Fig 5 for case 780. The results show that the abstraction rate that induced the upconing process was $0.49 \mathrm{~mL} / \mathrm{s}$ in case 1090 and $0.29 \mathrm{~mL} / \mathrm{s}$ in case 780 . This means the decrement of the hydraulic conductivity from $85 \mathrm{~cm} / \mathrm{min}$ (case 1090) to $36 \mathrm{~cm} / \mathrm{min}$ (case 780 ) induced a reduction of the critical pumping rate by $40 \%$.

In case 1090, Fig 4 shows that the freshwater-saltwater interface started to curve upward in a concave-like shape following the increment of the pumping rate to $Q=0.29 \mathrm{~mL} / \mathrm{s}$. A further rate increment to $\mathrm{Q}=0.39 \mathrm{~mL} / \mathrm{s}$ led the saline plume to pre-upconing stage, where the saline water became stable below the well. At this phase, the buoyancy force induced by density contrast effects was able to stabilise the wedge below the well without causing salinization of the latter. The final stage of the upconing was only be observed following the further increment of the pumping rate to $\mathrm{Q}=0.49 \mathrm{~mL} / \mathrm{s}$. Fig 5 shows the process in case 780 ; the upconing process was already initiated after the pumping rate was set to $\mathrm{Q}=0.19 \mathrm{~mL} / \mathrm{s}$. A further increase of the pumping rate to $Q=0.29 \mathrm{~mL} / \mathrm{s}$ was sufficient for the saline water to reach the well. These experimental observations suggest that the risk of salinization of freshwater abstraction wells increases with decreasing the hydraulic conductivity of the aquifer. These experimental results agree with the preliminary numerical results provided by Abdelgawad et al. (2018).

At first glance one may observe that the width of the transition zone remained relatively constant from one steady state to another before the initiation of the upconing process, i.e. before the upward motion of the saltwater (up to $\mathrm{Q}=0.29 \mathrm{~mL} / \mathrm{s}$ and $\mathrm{Q}=0.09 \mathrm{~mL} / \mathrm{s}$, in case 1090 and 780, respectively). This indicates that in the early phase of the upconing, the width of the transition zone was little sensitive to the rate of abstraction. The widening of the transition zone was only initiated as the freshwater-saltwater interface approached the vicinity 
of the well, i.e. after setting $\mathrm{Q}=0.39 \mathrm{~mL} / \mathrm{s}$ in case 1090 and $\mathrm{Q}=0.19 \mathrm{~mL} / \mathrm{s}$ in case 780 . The transition zone appeared slightly wider in case 780, probably due to the higher spreading along the interface as the saline water flows through finer grain size. The widening was visibly more pronounced in the upper part of the freshwater-saltwater interface. Once the upconing was completed, the width of the transition zone became very thin in case 1090. Similar observations were reported in previous studies (Mehdizadeh et al., 2015; Werner et al., 2009).

The transient toe length data of both cases are presented in Fig 6 and the steady state toe length values are shown in table 2 . The toe intrusion length increased with increasing the pumping rate. Prior to upconing, the data show that for equivalent pumping rate increment, the saline water intruded faster in case 780 . The results show that the intrusion length in case 780 was $7 \%$ and $41 \%$ greater than the toe length recorded in case 1090 for the rates $Q=0.09 \mathrm{~mL} / \mathrm{s}$ and $\mathrm{Q}=0.19 \mathrm{~mL} / \mathrm{s}$, respectively. In addition, for equivalent pumping rate increment, the net increase in toe length was greater in the early phase of the upconing process, but was reduced significantly as the saltwater wedge approached the location of the well (i.e. after setting $\mathrm{Q}=$ $0.39 \mathrm{~mL} / \mathrm{s}$ in case 1090 and $\mathrm{Q}=0.19 \mathrm{~mL} / \mathrm{s}$ in case 780 ). These results show that for equivalent pumping rate increment, the landward toe migration rate resulting from freshwater withdrawal was faster in the lower hydraulic conductivity system. 


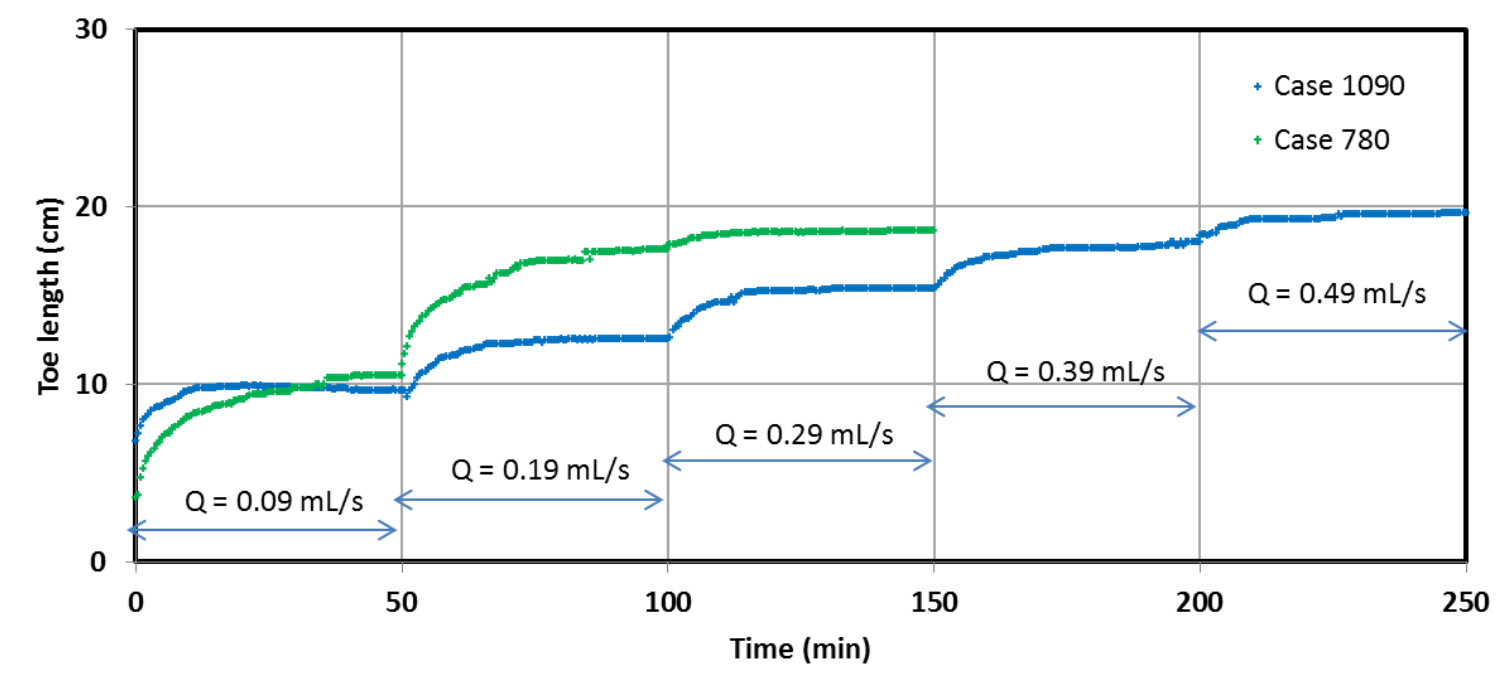

Figure 6 Transient experimental toe length data in cases 1090 (blue line) and case 780 (green line).

Table 2 Steady state toe length data in case 1090 , case 780

\begin{tabular}{lcccccc}
\hline Pumping rate (mL/s) & 0.09 & 0.19 & 0.29 & 0.39 & 0.49 \\
\hline \multirow{2}{*}{ Toe length $(\mathbf{c m})$} & Case 1090 & 9.8 & 12.5 & 15.4 & 18.0 & 19.6 \\
\cline { 2 - 7 } & Case 780 & 10.5 & 17.6 & 18.6 & -- & -- \\
\hline
\end{tabular}

Fig 7 shows the transient images of the early phase of the saltwater receding wedge phase. The saltwater receding phase was initiated after the pump was turned off. Following the interruption of the abstraction, the tip of the cone moved rapidly away from the well towards the seaside and the freshwater-saltwater interface subsequently regained its natural relatively straight shape. This mechanism was quicker in case 1090 as the greater seaward freshwater flow promoted by the higher permeability of the system allowed faster repulsion of the saltwater wedge towards the seaside. Fig 7 shows that a substantial widening of the transition zone was observable over the course of the retreat in both cases, albeit more pronounced in the lower permeability medium. The seaward migration of the toe of the saltwater wedge was also faster in case 1090, as observed in Fig 8. The results show that the saltwater toe reached steady state within $20 \mathrm{~min}$ and $29 \mathrm{~min}$, in case 1090 and case 780, respectively. This result suggests that the process of decay of the upconed saltwater wedge that follows the interuption of 
pumping would be slower in low permeability aquifer system, which implies a slower restoration of salinized aquifers.

In this study, the choice of a single point abstraction (from the tip of a thin needle) was preferred over the use of a well screen due to practical reasons, and because using a screened tube within the relatively thin width of the porous media chamber $(10 \mathrm{~mm})$ would cause significant disruption of the flow and thus impact the behaviour of the upconing wedge. Also, pumping from aquifer is a radial flow problem and therefore a pumping well is properly considered in a fully three-dimensional model, while the width of the tank was relatively thin $(10 \mathrm{~mm})$. It is nonetheless important to note that the purpose of this investigation is not to simulate the behaviour of saltwater wedge for a specific real aquifer system; rather it is to provide an insight on the influence of the aquifer permeability on the temporal evolution of saltwater upconing and decay mechanisms. Hence, although there is possibility that the walls of the tank might probably hinder the development of the cone of the depression in the third dimension at some time or rate of withdrawal, the results remains reliable for comparison purposes since all the experiments used the same aquifer geometry. Further investigation would be warranted to quantify the influence of the third dimension on the cone of depression and saltwater upconing dynamics. 

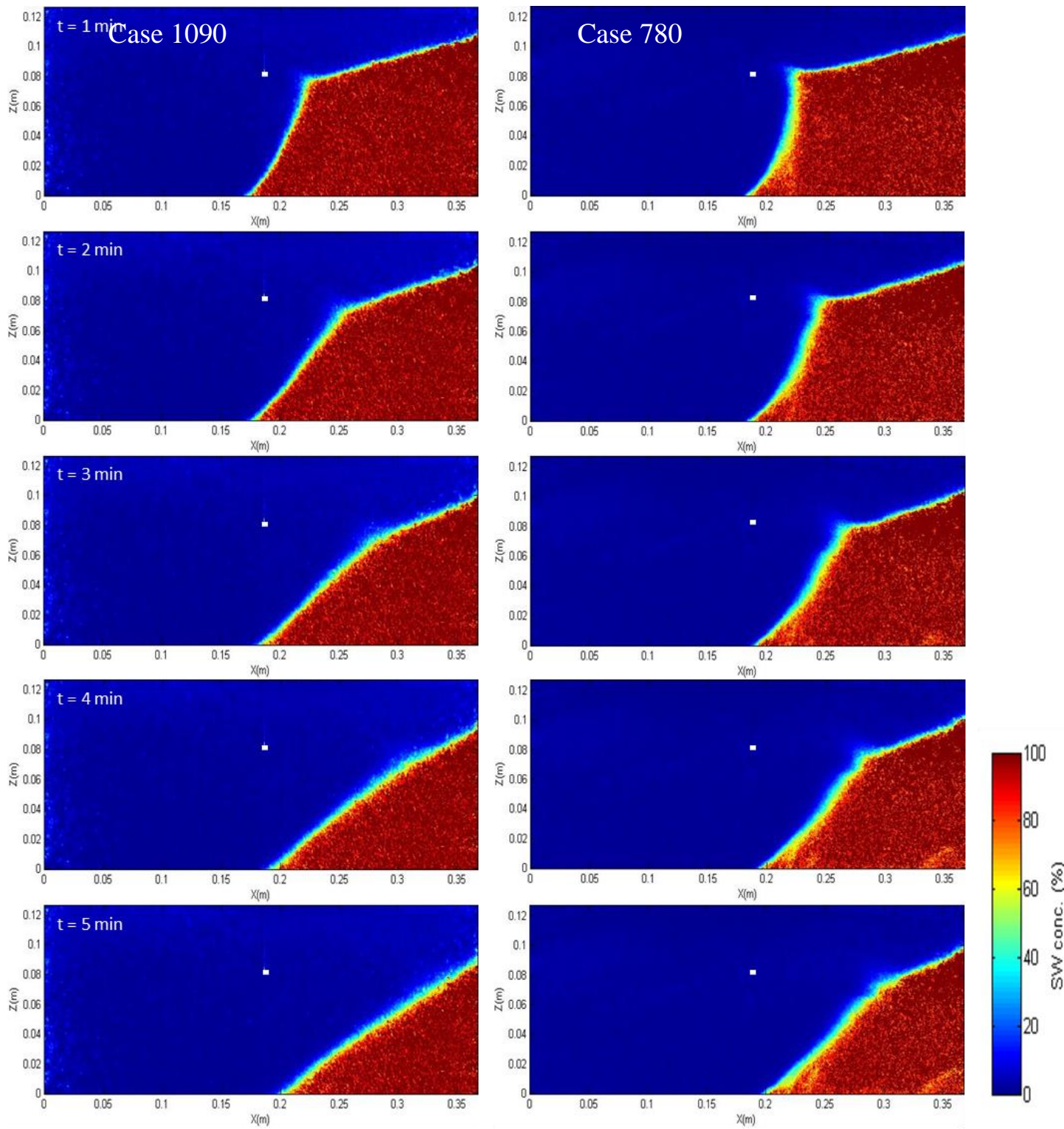

Figure 7 Transient experimental concentration colour maps showing the receding saltwater wedge after interruption of the pumping in case 1090 (left) and case 780 (right).

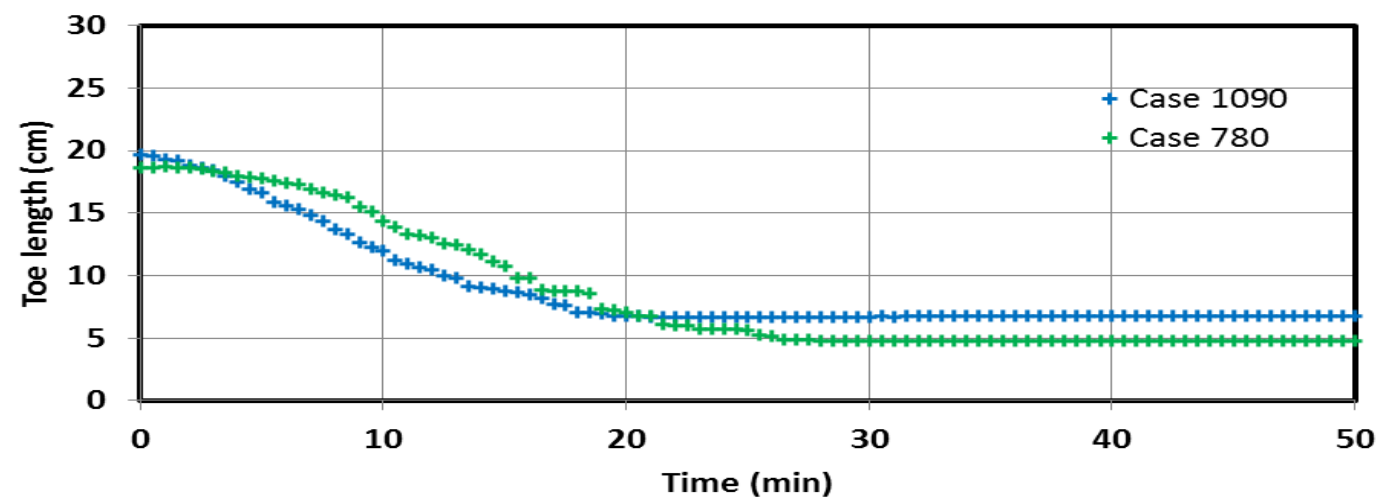

Figure 8 Transient experimental toe length data during the retreat process for case 1090 (blue line) and case 780 (green line). 
The experimental case 1090 was adopted for the numerical simulations. Unlike most of the previous studies that only relied on qualitative analysis of the wedge shape, the numerical validation was herein through both qualitative comparison of the shape of the saline plumes as well as quantitative comparison of the transient toe length data. This adds extra feature to this study. Fig 9 shows that the numerical model reproduced very well the shape of the steady state saltwater wedge throughout the different phases of the upconing process. The curved shape of the freshwater-saltwater interface prior to upconing was well reproduced in the numerical model. The widening of the upper portion of the interface observed as the saltwater wedge approached the well (after setting $\mathrm{Q}=0.39 \mathrm{~mL} / \mathrm{s}$ ) was also well depicted, albeit slightly overestimated in the numerical model. The model could predict relatively well the evolution from thin to wide transition zone conditions $(\mathrm{Q}=0.09-0.39 \mathrm{~mL} / \mathrm{s})$ that was observed in the physical experiment. The shape of the saltwater wedge at the final stage of the upconing was also very well depicted, despite some minor discrepancies observed at the seaside boundary. At the upconing stage, i.e. after the saline water reached the well, the transition zone in the numerical model became relatively thinner than at earlier stages, which agrees with the experimental observations. 


\subsection{Numerical modelling}
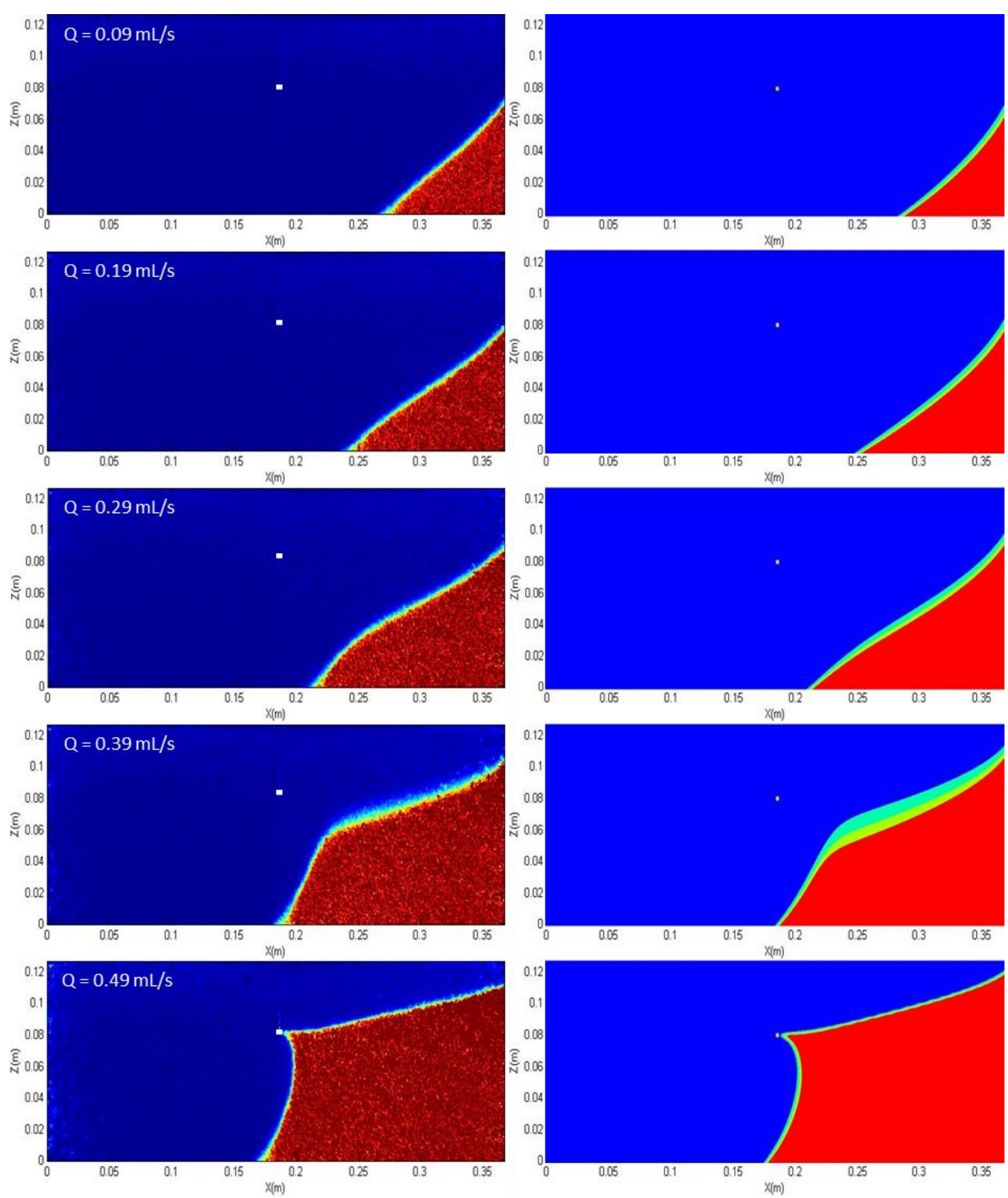

Figure 9 Comparison between experimental (left) and numerical (right) saltwater upconing process.

Fig 10 shows the comparison between the transient experimental toe length results and the numerical data. The experimental data matched very well with the numerical predictions. The toe length was slightly under-predicted at the start of the pumping $(\mathrm{t}=0-50 \mathrm{~min})$, while slightly over-predicted after application of the pumping rates $\mathrm{Q}=0.29 \mathrm{~mL} / \mathrm{s}$ and $\mathrm{Q}=0.39 \mathrm{~mL} / \mathrm{s}$. 
The minor discrepancies may be attributed to several factors, including possible minor source of heterogeneity associated with the packing of the beads, while the numerical model assumes perfect homogenous condition. Other factors such as tiny fluctuations in the water levels caused by surrounding vibrations may also contribute to this slight mismatch. Nonetheless, comparison shows in overall good agreement in the saltwater toe behaviour in response to the abstraction. The maximum percentage difference between experimental and numerical results was $8 \%, 1 \%, 7 \%, 6 \%, 2 \%$ and $1 \%$ for $\mathrm{Q}=0.09 \mathrm{~mL} / \mathrm{s}, 0.19 \mathrm{~mL} / \mathrm{s}, 0.29 \mathrm{~mL} / \mathrm{s}, 0.39 \mathrm{~mL} / \mathrm{s}$ and $0.49 \mathrm{~mL} / \mathrm{s}$, respectively.

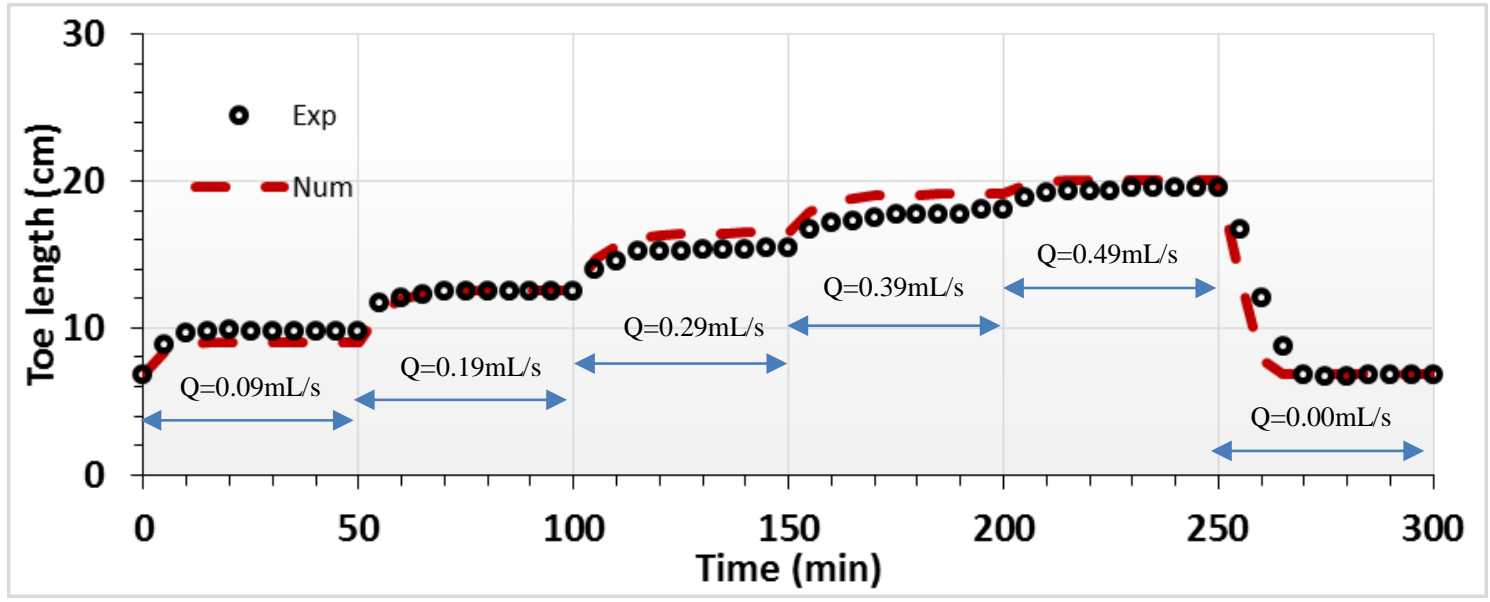

Figure 10 Comparison between transient experimental and numerical toe length data.

The maps of the flow velocity vectors are presented in Fig 11 to better understand the impact of the abstraction well on the flow and solute transport processes. The data show that prior to abstraction, the magnitude of the flow vectors is identical throughout the system, except in the top right zone where the freshwater exits with higher velocity, which is in agreement with other studies (e.g. Chang and Clement, 2012, Abdoulhalik and Ahmed, 2017a,b). The saltwater plume could be readily delineated by the vectors of very low magnitude at the bottom right corner. The initiation of the abstraction caused a subdivision of the flow domain into three distinct zones, each of which exhibiting different flow patterns in response to the withdrawal. 
These three zones are respectively located at the landward side of the well, in the vicinity of the well and the seaward side of the well (above the saline plume).
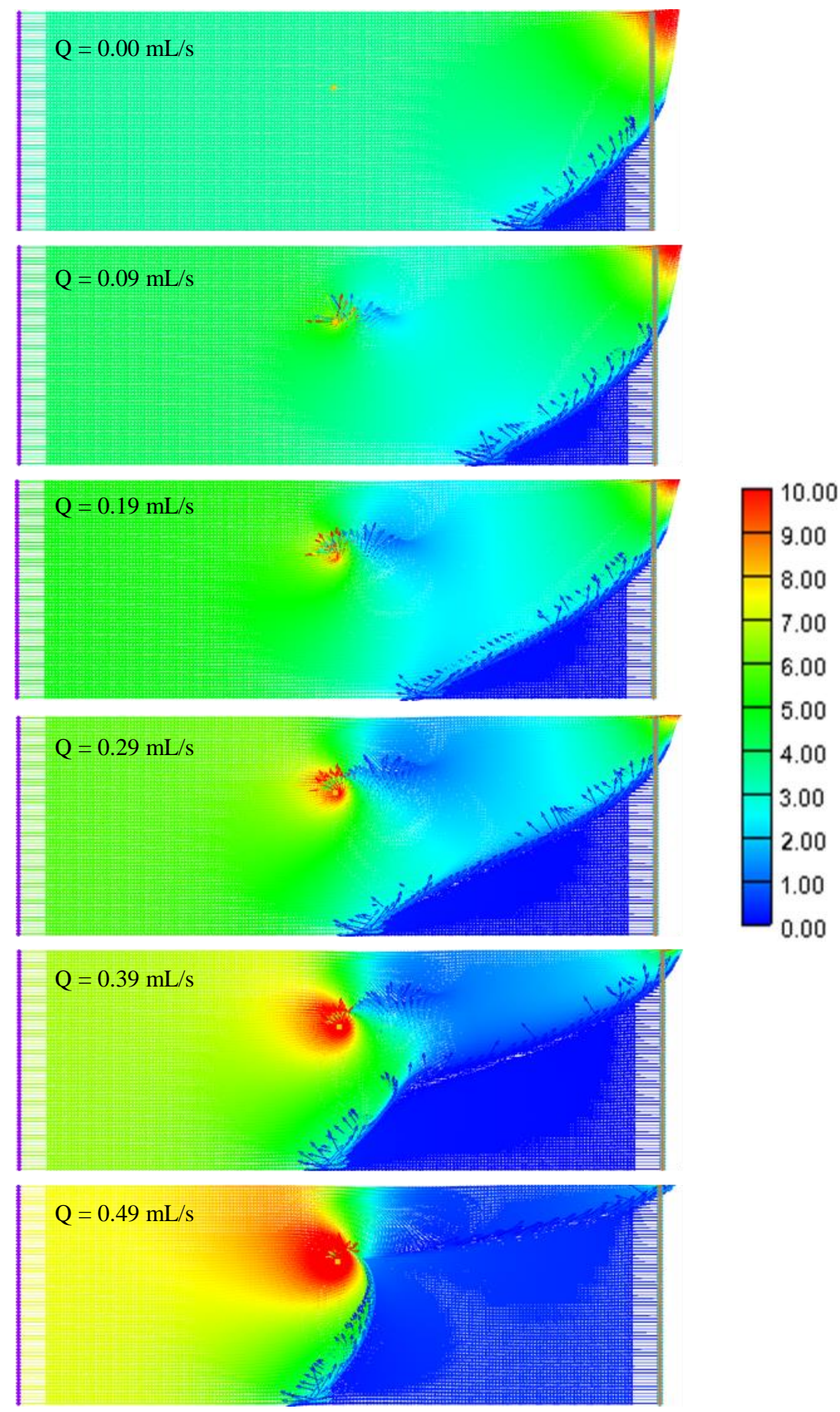

Figure 11 Maps of the flow velocity field during the upconing mechanism in the numerical model. The images were recorded at each steady state condition. The unit of the velocity is $\mathrm{cm} / \mathrm{min}$. 
When the abstraction was initiated, the magnitude of the vectors at the landward side of the well gradually increased from the inland boundary up to the vicinity of the well. The further increment of the pumping rate led to higher velocity within this region. In the vicinity of the well, a rather circular shape was initially formed within which the velocity substantially increased. The magnitude of the vectors reached very high values as the rate was further increased and the associated initial circular shape started to spread inland, with velocity increasing radially towards the well.

By contrast, the magnitude of the flow velocity in the seaward side of the well decreased noticeably, especially right beyond the position of the well. The magnitude of the flow velocity within this zone further decreased as the pumping rate was increased, thereby allowing the inland advancement of the saline wedge. The height of the saline plume along the coastline boundary was also further increased. The upconing saline plume was thus bounded on the top part by very low flow velocity and on the landward side by relatively high flow velocity, which resulted in this outward dipping shape of interface $(t=250 \mathrm{~min})$. The upconing was completed as the dipping part of the interface reached the zone of high velocity around the well, where the water is abstracted.

\subsection{Summary and conclusions}

Experiments were conducted within laboratory flow tank to examine the effect of permeability on saltwater upconing mechanism in inclined freshwater-saltwater interface model. The investigation involved the analysis of two homogeneous porous media of different bead sizes. Automated image analysis techniques were implemented to enable a qualitative and quantitative analysis of the effect of freshwater pumping on the saltwater upconing behaviour. This allowed uncovering crucial details of the transient behaviour of the freshwater-saltwater transition zone with high spatial and temporal resolution. The SEAWAT code was used for the numerical simulations. The main findings of the study could be summarized as follows: 
- The saltwater upconing process was observed with an abstraction rate $40 \%$ smaller in the lower hydraulic conductivity scenario. In addition, the inland penetration of the saline plume was larger in the lower $\mathrm{K}$ scenario relative to the higher $\mathrm{K}$ scenario, for equivalent pumping rate increment. The intrusion length for the $780 \mu \mathrm{m}$ beads was $7 \%$ and $41 \%$ greater than the toe length recorded for the $1090 \mu \mathrm{m}$ beads for abstraction rates $\mathrm{Q}=0.09 \mathrm{~mL} / \mathrm{s}$ and $\mathrm{Q}=0.19$ $\mathrm{mL} / \mathrm{s}$, respectively.

- In each case, the net increase in toe length was greater in the early phase of the upconing process, but reduced significantly as the saltwater wedge approached the location of the well (i.e. after setting $\mathrm{Q}=0.39 \mathrm{~mL} / \mathrm{s}$ in case 1090 and $\mathrm{Q}=0.19 \mathrm{~mL} / \mathrm{s}$ in case 780 ), despite the magnitude of increase in the pumping rate was the same. The widening of the freshwatersaltwater transition zone was observed only as the saltwater wedge approached the well location and was more pronounced along the upper part of the interface length, with a more pronounced widening in the low $\mathrm{K}$ scenario.

- The process of decay (following the pumping switch off) of the upconed wedge was slower in the low permeability aquifer compared to the high permeability aquifer.

- The comparison between the numerical simulation results and the experimental data showed excellent agreement for both the transient toe length data and the shape of the steady state saltwater wedges for all the pumping rates applied to our inclined freshwater-saltwater interface model. Such quantitative matching adds extra feature to this study.

- The flow velocity field analysis revealed that local reduction of the magnitude of the flow velocity along the upper part of the interface was a major factor contributing to the upconing mechanism. This allowed the "free" vertical rise of the saline plume due to the subsequent reduction of the repulsion forces of the seaward freshwater flow. The relatively high flow velocity below the well resulted in this outward dipping shape of interface which yielded 
upconing when the tip reached the zone of high velocity vectors around the well, where the water is abstracted.

The findings reported in the study are very valuable for water resources managers and decision makers, as they provide for the first time experimental evidence that pumping wells in low permeability aquifer systems are more vulnerable to salinization through upconing process compared to high permeability aquifers. In addition, the study also suggests that the recovery of salinized aquifers would be slower in low permeability aquifer systems after interruption of the pumping well, which implies a longer time required before it is possible to reuse the fresh groundwater again. Future work would nonetheless be required to further support these findings, which would involve larger and/or 3D aquifer models. Also, additional investigations of saltwater upconing mechanism in more complicated scenarios, involving for instance typical subsurface heterogeneity effects would also be very beneficial. These investigations are currently ongoing by the authors and will be the topics of forthcoming publications.

\section{Acknowledgments}

The authors wish to thank Abdelrahman Abdelgawad for his support in the numerical modelling. We thank the two anonymous reviewers and the editor for their comments that helped improve this manuscript. We acknowledge the support from Queen's University Belfast by the mean of a PhD studentship accorded to the first author.

\section{References}

Abdelgawad, A., Abdoulhalik, A., Ahmed, A., Moutari, S. and Hamill, G. A., (2018). Transient Investigation of the Critical Pumping Rate in Laboratory-Scale Coastal Aquifer, Water Resources Management. doi: 10.1007/s11269-018-1988-3

Abdoulhalik, A. and Ahmed, A. A. (2017a). The effectiveness of cutoff walls to control saltwater intrusion in multi-layered coastal aquifers: Experimental and numerical study. Journal of Environmental Management, 199, 62-73. doi: 10.1016/j.jenvman.2017.05.040.

Abdoulhalik, A., Ahmed, A.A., (2017b). How does layered heterogeneity affect the ability of subsurface dams to clean up coastal aquifers contaminated with seawater intrusion? Journal of Hydrology, 553, 708-721. doi:10.1016/j.jhydrol.2017.08.044

Abdoulhalik, A., Ahmed, A.A., (2018). Transience of seawater intrusion and retreat in response to incremental water-level variations. Hydrological Processes 1-13, https://doi.org/10.1002/hyp.13214 
Abdoulhalik, A., Ahmed, A. and Hamill, G. A. (2017). A new physical barrier system for seawater intrusion control. Journal of Hydrology, 549, 416-427. doi:

10.1016/j.jhydrol.2017.04.005.

Chang, S.W., Clement, T.P.(2012). Experimental and numerical investigation of saltwater intrusion dynamics in flux-controlled groundwater systems. Water Resources Research, 48, W09527.

Dagan, G. and Bear, J. (1968). Solving the problem of local interface upconing in a coastal aquifer by the method of small perturbations. Journal of Hydraulic Research. doi: $10.1080 / 00221686809500218$.

De Louw, P.G.B., Vandenbohede, A., Werner, A.D., Oude Essink, G.H.P. (2013). Natural saltwater upconing by preferential groundwater discharge through boils. Journal of Hydrology. 490, 74-87.

Ferguson, G., Gleeson, T., (2012). Vulnerability of coastal aquifers to groundwater use and climate change. Nature Climate Change. 2, 342-345.

Guo, W., Langevin, C.D., (2002). User's guide to SEAWAT; a computer program for simulation of three-dimensional variable-density ground-water flow.

Harbaugh, A.W., Banta, E.R., Hill, M.C., McDonald, M.G., (2000). MODFLOW-2000, The U. S. Geological Survey Modular Ground-Water Model-User Guide to Modularization Concepts and the Ground-Water Flow Process. Open-file Report.U.S.Geological Survey., 134.

Jakovovic, D., Werner, A. D. and Simmons, C. T. (2011). Numerical modelling of saltwater up-coning: Comparison with experimental laboratory observations. Journal of Hydrology, 402(3-4), 261-273. doi: 10.1016/j.jhydrol.2011.03.021.

Johannsen, K. et al. (2002). The saltpool benchmark problem - Numerical simulation of saltwater upconing in a porous medium. Advances in Water Resources, 25(3), 335-348. doi: 10.1016/S0309-1708(01)00059-8.

Kashef, A.-A. I. and Smith, J. C. (1975). Expansion of salt-water zone dut to well discharge. Journal of the American Water Resources Association, 11(6), 1107-1120. doi: 10.1111/j.1752-1688.1975.tb01834.x.

Langevin, C.D., Shoemaker, W.B., W.B., Guo, W., (2003). MODFLOW-2000, the US Geological Survey Modular Ground-Water Model--Documentation of the SEAWAT-2000 Version with the Variable-Density Flow Process (VDF) and the Integrated MT3DMS Transport Process (IMT). USGS Open-File Report 03-426. Tallahassee, Florida.

Mehdizadeh, S. S., Vafaie, F. and Abolghasemi, H. (2015). Assessment of sharp-interface approach for saltwater intrusion prediction in an unconfined coastal aquifer exposed to pumping. Environmental Earth Sciences, 73(12), 8345-8355. doi: 10.1007/s12665-0143996-9.

Noorabadi, S. et al. (2017). Laboratory investigation of water extraction effects on saltwater wedge displacement. Global Journal of Environmental Science and Management-Gjesm, 3(1), 21-32. doi: 10.22034/gjesm.2017.03.01.003.

Oswald, S. E. and Kinzelbach, W. (2004). Three-dimensional physical benchmark 
experiments to test variable-density flow models. Journal of Hydrology, 290(1-2), 22-42. doi: 10.1016/j.jhydrol.2003.11.037.

Reilly, T. E. and Goodman, A. S. (1987). Analysis of saltwater upconing beneath a pumping well. Journal of Hydrology, 89(3-4), 169-204. doi: 10.1016/0022-1694(87)90179-x.

Robinson, G., Hamill, G. A. and Ahmed, A. A. (2015). Automated image analysis for experimental investigations of salt water intrusion in coastal aquifers. Journal of Hydrology, 530, 350-360. doi: 10.1016/j.jhydrol.2015.09.046.

Robinson G, Ahmed AA, Hamill GA. (2016). Experimental saltwater intrusion in coastal aquifers using automated image analysis: Applications to homogeneous aquifers. Journal of Hydrology, 538:304-313.

Schmork, S. and Mercado, A. (1969). Upconing of fresh water-sea water interface below pumping wells, field study. Water Resources Research, 5(6), 1290-1311. doi: 10.1029/WR005i006p01290.

Shi, L. et al. (2011) 'Applicability of a sharp-interface model for estimating steady-state salinity at pumping wells — validation against sand tank experiments', Journal of Contaminant Hydrology. 124(1-4), 35-42. doi: 10.1016/j.jconhyd.2011.01.005.

Stoeckl, Leonard, Houben, Georg. (2012). Flow dynamics and age stratification of freshwater lenses: Experiments and modeling, Journal of Hydrology, 458-459, 9-15. doi.org/10.1016/j.jhydrol.2012.05.070.

Voss, C.I., Souza, W.R., 1987. Variable density flow and solute transport simulation of regional aquifers containing a narrow freshwater-saltwater transition zone. Water Resources Research, 23, 1851-1866.

Werner, A. D., Jakovovic, D. and Simmons, C. T. (2009) 'Experimental observations of saltwater up-coning', Journal of Hydrology. 373(1-2), 230-241. doi:

10.1016/j.jhydrol.2009.05.004.

Werner, A.D., Bakker, M., Post, V.E., Vandenbohede, A., Lu, C., Ataie-Ashtiani, B., Simmons, C.T. and Barry, D.A. (2013). Seawater intrusion processes, investigation and management: recent advances and future challenges. Advances in Water Resources, 51, 3-26.

WHO, (2011). Guidelines for drinking-water quality. World Health Organization. 216, 303304.

Wirojanagud, P. and Charbeneau, R. J. (1985). Saltwater upconing in unconfined aquifers. Journal of Hydraulic Engineering, 111(3), 417-434. doi: 10.1061/(ASCE) 07339429(1985)111:3(417).

Zheng, C., Wang, P.P., (1999). MT3DMS: a modular three-dimensional multispecies transport model for simulation of advection, dispersion, and chemical reactions of contaminants in groundwater systems. 